\title{
Altitude misestimation caused by the Vaisala RS80 pressure bias and its impact on meteorological profiles
}

\author{
Y. Inai ${ }^{1, a}$, M. Shiotani ${ }^{1}$, M. Fujiwara ${ }^{2}$, F. Hasebe ${ }^{2}$, and H. Vömel ${ }^{3}$ \\ ${ }^{1}$ Research Institute for Sustainable Humanosphere, Kyoto University, Uji, Japan \\ ${ }^{2}$ Faculty of Environmental Earth Science, Hokkaido University, Sapporo, Japan \\ ${ }^{3}$ Earth Observing Laboratory, The National Center for Atmospheric Research, Boulder, USA \\ ${ }^{a}$ now at: Faculty of Environmental Earth Science, Hokkaido University, Sapporo, Japan \\ Correspondence to: Y. Inai (yoichi_inai@ees.hokudai.ac.jp)
}

Received: 4 February 2015 - Published in Atmos. Meas. Tech. Discuss.: 25 February 2015

Revised: 6 September 2015 - Accepted: 12 September 2015 - Published: 2 October 2015

\begin{abstract}
Previous research has found that conventional radiosondes equipped with a traditional pressure sensor can be subject to a pressure bias, particularly in the stratosphere. This study examines this pressure bias and the resulting altitude misestimation, and its impact on temperature, ozone, and water vapor profiles is considered using data obtained between December 2003 and January 2010 during the Soundings of Ozone and Water in the Equatorial Region (SOWER) campaigns. The payload consisted of a radiosonde (Vaisala RS80), ozone and water vapor sondes, and a global positioning system (GPS) sensor. More than 30 soundings are used in this study. As GPS height data are thought to be highly accurate, they can be used to calculate pressure. The RS80 pressure bias in the tropical stratosphere is estimated to be $-0.4 \pm 0.2 \mathrm{hPa}(1 \sigma)$ between 20 and $30 \mathrm{~km}$. As this pressure bias is negative throughout the stratosphere, it leads to systematic overestimation of geopotential height by $43 \pm 23$, $110 \pm 40$, and $240 \pm 92 \mathrm{~m}(1 \sigma)$ at 20,25 , and $30 \mathrm{~km}$, respectively when it is calculated by using the hypsometric equation. Because of the altitude overestimation, we see some offsets in observation parameters having a vertical gradient such as temperature, ozone, and water vapor. Those offsets in the meteorological soundings obtained using the RS80 may have generated an artificial trend in the meteorological records when radiosondes were changed from the RS80, which had no GPS unit, to the new ones with a GPS unit. Therefore, it is important to take those offsets into account in climate change studies.
\end{abstract}

\section{Introduction}

Radiosondes are one of the most important observation tools used in meteorological studies to measure in situ temperature, pressure, humidity, and horizontal wind above the surface up to around $30 \mathrm{~km}$. There are many vendors supplying radiosondes for operational and scientific observations, and extensive intercomparisons have been conducted (Nash and Schmidlin, 1987; Nash et al., 2006, 2011; Ivanov et al., 1991; Yagi et al., 1996; da Silveira et al., 2006).

Traditionally, the hypsometric equation has been used to calculate height information from pressure, temperature, and humidity measurements. Currently, however, global positioning system (GPS) technology is used for altitude derivation, and pressure is inversely derived from the GPS height data (Jannet et al., 2008). Over the past decade, the oldtype radiosondes, which have no GPS receiver, have been replaced by new-type radiosondes with a GPS receiver.

The Vaisala RS80 radiosonde has been used worldwide since 1981, and their market share was $48 \%$ of all radiosonde stations globally as of March 2002 (Elms, 2003). Recently, it has been reported that the RS80 radiosonde shows a negative pressure bias in the stratosphere (e.g., Steinbrecht et al., 2008; Inai et al., 2009). Such a negative pressure bias could cause height overestimation; i.e., estimated heights being greater than the actual height. Moreover, this results in a negative temperature offset at a given altitude in the stratosphere, where temperature increases with increasing height. Steinbrecht et al. (2008) suggested that this RS80 negative pressure bias, together with the changeover to the Vaisala RS92, 
which is an updated version of the RS80, could lead to a discontinuity in the stratospheric temperature record.

We note here that there are two comparison methods for the measurements from two radiosondes (or ozonesondes or water vapor sondes) which were flown simultaneously with a single balloon. The first one is the "simultaneous sensor comparison" (i.e., at the same time during a flight or for the same air parcel) which is used, e.g., during the World Meteorological Organization (WMO) Radiosonde Intercomparison Campaigns (e.g., Nash et al., 2011). This is appropriate, for example, to evaluate the performance of relative humidity sensors from different radiosonde types. However, the results cannot be readily used for data homogenization because this method does not inherently reveal any potential issues in association with height estimation. If one wants to carefully analyze radiosonde data for some specific period including the instrument switchover from old type to new one, the other comparison method should be used. That is the "comparison on pressure (or altitude or geopotential height) levels" by taking into account vertical profile shifts arising from the different performance in pressure sensors, as performed by, e.g., Steinbrecht et al. (2008) and Kobayashi et al. (2012).

Stauffer et al. (2014) discussed possible errors in ozone profiles caused by pressure biases from various types of conventional radiosondes, including the RS80. In their Figs. 2, 3, and 10, they actually showed "biased" mixing ratio of ozone plotted on "biased" altitude; however, in their Fig. 7, they showed errors arising when "biased" mixing ratio is plotted on "correct" altitude, which is indicated as "GPS Altitude". In other words, they evaluated the ozone mixing ratio errors in their Fig. 7 by subtracting the "correct" ozone profile plotted on "correct" altitude from the "biased" ozone profile plotted on "correct" altitude at the same altitude. This error calculation is equivalent to the "simultaneous sensor comparison" as explained above, because the two profiles use the same vertical axis based on the same GPS measurements.

In contrast, in this paper we evaluate observational errors for conventional soundings and to consider artificial offsets in the meteorological records associated with the transition from a period when radiosondes have no GPS unit to a period when they have a GPS unit. This has to be done by the "comparison on pressure (actually geopotential height in our study) levels" as described above. We also compare our results with those of Stauffer et al. (2014). In this study, we show the impact of the vertical shift on observed temperature profiles (in Sect. 3.1), ozone profiles (in Sect. 3.2), and water vapor profiles (in Sect. 3.3) based on measurements made with an RS80 radiosonde, as well as water vapor and ozone sondes with a GPS unit, obtained during the Soundings of Ozone and Water in the Equatorial Region (SOWER) campaigns.

\section{Data and pressure bias}

The SOWER campaigns in the tropical western $\mathrm{Pa}$ cific/Indonesian region have been conducted in every boreal winter since December 2001 to study processes in the tropical tropopause layer (TTL) (e.g., Fujiwara et al., 2010; Inai et al., 2012; Shibata et al., 2012; Hasebe et al., 2013; Inai et al., 2013). During the SOWER campaigns, 33 successful soundings were conducted with the combined use of an RS80 radiosonde, an electrochemical concentration cells (ECC) ozonesonde together with a GPS unit, and a chilledmirror hygrometer, from December 2003 to January 2010. All of the GPS units were provided by the Garmin Ltd. and situated in the lid of the Environmental Science Corporation (En-Sci) ECC ozonesondes. These data are used in this study (Table 1). We estimate the RS80 pressure bias using these data following the method of Inai et al. (2009), and thus examine how the RS80 pressure bias affects profiles of meteorological parameters such as temperature, ozone, and water vapor. A preliminary consideration of this issue was briefly reported in Imai et al. (2013), but in this paper we present our viewpoint and approach in detail.

Note that the SOWER data were not obtained using the genuine Vaisala system, which automatically corrects pressure data with an independent ground-based barometer, and the SOWER data used in this paper were consolidated according to our quality control (QC) procedure to ensure their uniformity. These data have also been used in previous studies such as Inai et al. (2009) and Imai et al. (2013); the QC procedure is summarized in Appendix A.

Whereas a GPS unit reports an altitude (GPS altitude $\equiv z_{\mathrm{GPS}}$ ) above the WGS-84 ellipsoid (NIMA, 2000), the geometric altitude $(z)$ is defined by the absolute altitude above mean sea level (a.m.s.l.). The geometric altitude $z$ can be converted to geopotential height $Z$ (e.g., Mahoney, 2005), which is used as a vertical coordinate for conventional meteorological data set. In this study, we obtain the geopotential heights from $z_{\text {GPS }}$ by using the station altitude (a.m.s.l.) as the initial GPS altitude. Thus, the precision of $Z$ is the same as that of $z_{\mathrm{GPS}}$, and is accurate to within approximately $20 \mathrm{~m}$ between the surface and a height of $34 \mathrm{~km}$ (Nash et al., 2006). In the following, we use $Z$ values obtained from the GPS as a reference vertical coordinate.

Alternatively, using vertical profile data for pressure $(p$, $\mathrm{N} \mathrm{m}^{-2}$ ), temperature $(T, \mathrm{~K})$, and relative humidity (RH: $U$ in \%), we can obtain the geopotential height, $Z_{\mathrm{PTU}}$, by hypsometric equation (e.g., Holton, 2004):

$Z_{\mathrm{PTU}}(p)=-\int_{p_{0}}^{p} \frac{R_{\mathrm{d}} T}{g_{0}} \frac{1}{p^{\prime}+\frac{U}{100} p_{\mathrm{ws}}\left(\frac{M_{\mathrm{w}}-M_{\mathrm{d}}}{M_{\mathrm{d}}}\right)} \mathrm{d} p^{\prime}+Z_{0}$.

Here, $R_{\mathrm{d}}$ is the specific gas constant for dry air $\left(287.05 \mathrm{~J} \mathrm{~K}^{-1} \mathrm{~kg}^{-1}\right), g_{0}$ is the standard acceleration of gravity $\left(9.80665 \mathrm{~m} \mathrm{~s}^{-2}\right), M_{\mathrm{d}}$ is the molecular weight of dry air $\left(28.964 \mathrm{~kg} \mathrm{kmol}^{-1}\right), M_{\mathrm{w}}$ is that of water vapor 


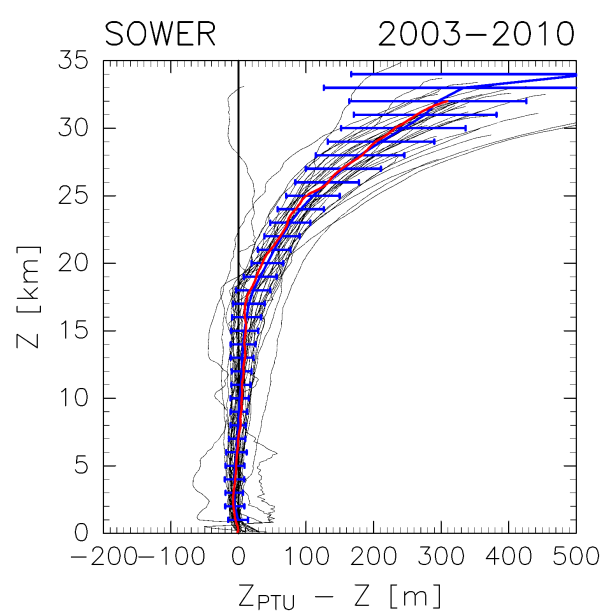

Figure 1. Differences between $Z_{\mathrm{PTU}}$ and $Z$ ( $Z_{\mathrm{PTU}}$ minus $Z$ ) for all soundings in Table 1 (black lines) and for BI048 observations, which are shown in Figs. 3, 5, and 7 as an example (red line). The blue line and horizontal bars indicate the mean difference and 1 standard deviation calculated at each altitude, respectively.

$\left(18.015 \mathrm{~kg} \mathrm{kmol}^{-1}\right), p_{\mathrm{ws}}$ is the saturation water vapor partial pressure $\left[\mathrm{N} \mathrm{m}^{-2}\right]$ at temperature $T$, and $p_{0}$ and $Z_{0}$ are the pressure and geopotential height (a.m.s.l.) at the first step of the integration, respectively. As $Z_{\mathrm{PTU}}$ is calculated from PTU, the precision and accuracy depend on those of the pressure, temperature, and humidity sensors. Inai et al. (2009) showed that among these parameters, the accuracy of the pressure sensor is essential in the stratosphere. The Humicap sensor is reliable only up to about $12 \mathrm{~km}$, and the $\mathrm{RH}$ values reported by RS80 in the stratosphere is always higher than the actual values. The error of RH sensors in the stratosphere, however, has little influence on our analysis. For example, if we calculate $Z_{\text {PTU }}$ with $U=0$ above the $200 \mathrm{hPa}$ level, the difference from original $Z_{\mathrm{PTU}}$ (with reported $\mathrm{RH}$ ) becomes only $3 \mathrm{~cm}$ at $30 \mathrm{~km}$. So we used RH values reported by the RS80 radiosonde also in the stratosphere for geopotential height calculation in this analysis.

Figure 1 shows the differences between $Z_{\mathrm{PTU}}$ and $Z$ at the same observation time for all soundings listed in Table 1. Although the difference is small $(\sim 20 \mathrm{~m})$ in the troposphere, it becomes larger in the stratosphere with a difference of $\sim 240 \mathrm{~m}$ at $30 \mathrm{~km}$ on average. A similar offset of $Z_{\mathrm{PTU}}$ was reported and discussed by Inai et al. (2009). In the present analysis, the data period was extended to include the 2010 campaign, but data from Hanoi, located in the subtropics, were excluded because we now have sufficient sounding data even from the tropics. The following section shows a typical example of sounding profile (BI048), which is highlighted by a red line in Fig. 1.

Steinbrecht et al. (2008) reported a similar profile of geopotential height error of RS80 but their result differs by approximately $-30 \mathrm{~m}$ in whole height region from our result and has larger error bars in the stratosphere. Here, we esti-

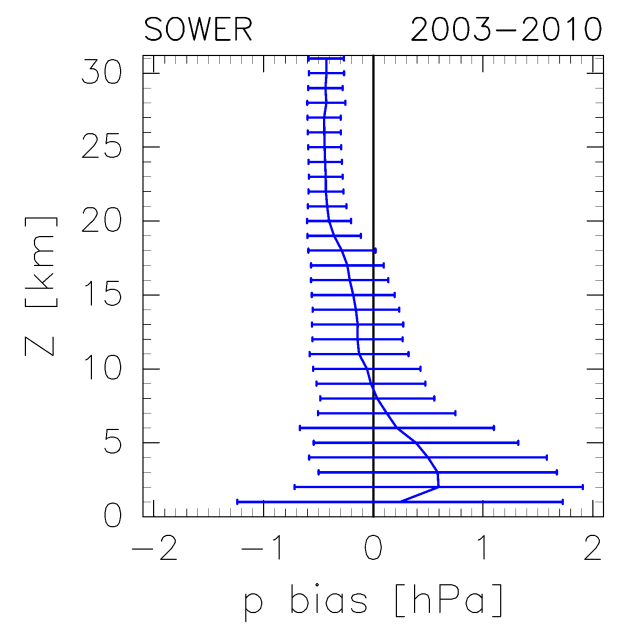

Figure 2. RS80 pressure bias estimated for all soundings listed in Table 1. Horizontal bars show 1 standard deviation.

Table 1. Number of successful soundings by the SOWER campaign between December 2003 and January 2010, and the locations of campaign sites.

\begin{tabular}{llr}
\hline Station & Location (long./lat.) & Soundings \\
\hline Kototabang & $\left(100.3^{\circ} \mathrm{E}, 0.2^{\circ} \mathrm{S}\right)$ & 6 \\
Bandung & $\left(107.6^{\circ} \mathrm{E}, 6.9^{\circ} \mathrm{S}\right)$ & 4 \\
Biak & $\left(136.1^{\circ} \mathrm{E}, 1.2^{\circ} \mathrm{S}\right)$ & 16 \\
Tarawa & $\left(172.9^{\circ} \mathrm{E}, 1.4^{\circ} \mathrm{N}\right)$ & 7 \\
\hline
\end{tabular}

mate the uncertainty of our results coming from temperature and $\mathrm{RH}$ uncertainties corresponding to the RS80 manufacturer's specifications on our calculation of $Z_{\mathrm{PTU}}$. As a result, temperature uncertainty of $0.20^{\circ} \mathrm{C}$ below the $50 \mathrm{hPa}$ level, $0.30^{\circ} \mathrm{C}$ from 50 to $15 \mathrm{hPa}, 0.40^{\circ} \mathrm{C}$ above the $15 \mathrm{hPa}$ level and RH uncertainty of $3 \%$ produce $34 \mathrm{~m}$ of $Z_{\text {PTU uncertainty at }}$ $30 \mathrm{~km}$. Since this is about one-third as much magnitude as the error bar shown in Fig. 1, namely, $90 \mathrm{~m}$ at $30 \mathrm{~km}$, we believe the temperature and RH uncertainties do not have significant influence on our analysis.

In recent years, almost all radiosonde systems have used GPS height information together with temperature and humidity to derive pressure ( $\left.p_{\mathrm{GPS}}\right)$. In this study, we calculate $p_{\mathrm{GPS}}$ based on the differential form of Eq. (1). To avoid perturbed results from the differential equation, we calculate $p_{\mathrm{GPS}}$ after taking the \pm 1 min running mean of the GPS height, temperature, and humidity to smooth the profile; the same smoothing was applied to Eq. (1) for consistency. The \pm 1 min smoothing is a different procedure from Stauffer et al. (2014), who used $1 \mathrm{~km}$ median value due to noisy data. If we assume that the typical ascending speed of soundings is $5 \mathrm{~m} \mathrm{~s}^{-1}$, the vertical resolution of our smoothing is about $600 \mathrm{~m}$ which is somewhat smaller than that of Stauffer et al. (2014). 
Figure 2 shows the statistical feature of the pressure bias; i.e., the differences between observed pressure $(p)$ and GPSderived pressure ( $p_{\mathrm{GPS}}$ ), at the same observation time from the SOWER soundings listed in Table 1. This figure shows that the RS80 pressure bias is significantly negative in the upper troposphere and stratosphere, and is $-0.4 \pm 0.2 \mathrm{hPa}(1 \sigma)$ between 20 and $30 \mathrm{~km}$. The bias is positive in the lower troposphere, but the uncertainty is large.

This means that we may not be able to eliminate the RS80 pressure biases using a constant pressure correction because the RS80 pressure biases may not be constant with altitude particularly in the troposphere.

Note that the characteristics apparent in Fig. 2 may be a restrictive result from the SOWER data, because the instrumental propensity of the RS80 could depend on the production lots to some degree.

Nonetheless, Steinbrecht et al. (2008) also reported a similar bias for the RS80 in the stratosphere; they showed that the biases are $-0.25 \mathrm{hPa}$ at $30 \mathrm{hPa}$ and $-0.5 \mathrm{hPa}$ at $10 \mathrm{hPa}$.

On the other hand, Stauffer et al. (2014) showed that the RS80 pressure biases were $-1 \mathrm{hPa}$ in the stratosphere which is larger than that estimated in this study, and the pressure biases have no dependence on the sonde production date. They also estimated that it is larger than that of the RS92, and is similar to the International Met Systems (iMet) series. Here note that even if we do not make our all QC procedures, the estimated pressure biases are $-0.3 \pm 1.0,-0.3 \pm 1.1$, and $-0.5 \pm 1.0 \mathrm{hPa}(1 \sigma)$ at 20,25 , and $30 \mathrm{~km}$, respectively. Thus the results do not change significantly and they are also still different from the result in Stauffer et al. (2014).

As described in Sect. 1, Stauffer et al. (2014) discussed the influence of pressure bias on the ozone mixing ratio, but they did not take into account an altitude offset caused by the pressure bias when they evaluated the ozone mixing ratio error (their Fig. 7) as pointed out by Shiotani (2013) as a comment on the discussion paper by Stauffer et al. (2014). In the following sections, errors in temperature, ozone, and water vapor profiles resulting from the RS80 pressure bias are estimated and discussed in detail.

\section{Impact of pressure bias on observed profiles}

\subsection{Temperature}

In Sect. 2, pressure bias in the RS80 was discussed on the basis of differences between observed $p$ and $p_{\mathrm{GPS}}$, and between $Z_{\text {PTU }}$ and $Z$. As clearly shown in Fig. $1, Z_{\text {PTU sys- }}$ tematically differs from $Z$, and this altitude misestimation can affect all meteorological profiles when we only have altitude information from PTU, $Z_{\mathrm{PTU}}$. First, we focus on the temperature profile in this subsection.

The left panel of Fig. 3 shows two temperature profiles: $T$ ( $\left.Z_{\mathrm{PTU}}\right)$ (blue dashed line) and $T(Z)$ (red line), along the vertical coordinates of $Z_{\text {PTU }}$ and $Z$, respectively. The origi-
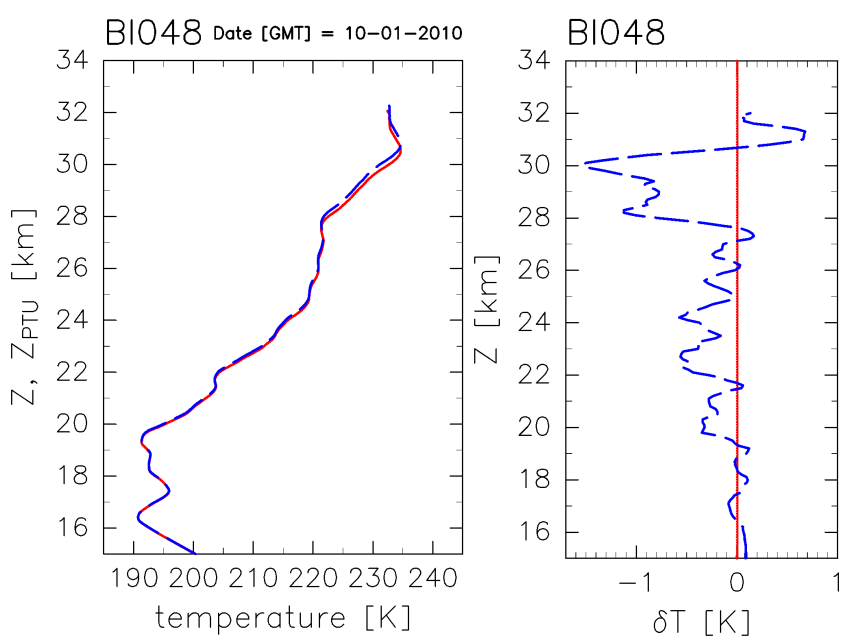

Figure 3. (Left) Example of temperature profiles based on $Z_{\mathrm{PTU}}$ $\left(T\left(Z_{\mathrm{PTU}}\right) \equiv T_{\mathrm{PTU}}(Z)\right.$; blue dashed line $)$ and $Z(T(Z)$; red line $)$ measured over Biak on 10 January 2010. (Right) Difference between the two temperature profiles in the left panel, defined as $T_{\mathrm{PTU}}(Z)$ minus $T(Z)$ (blue dashed line).

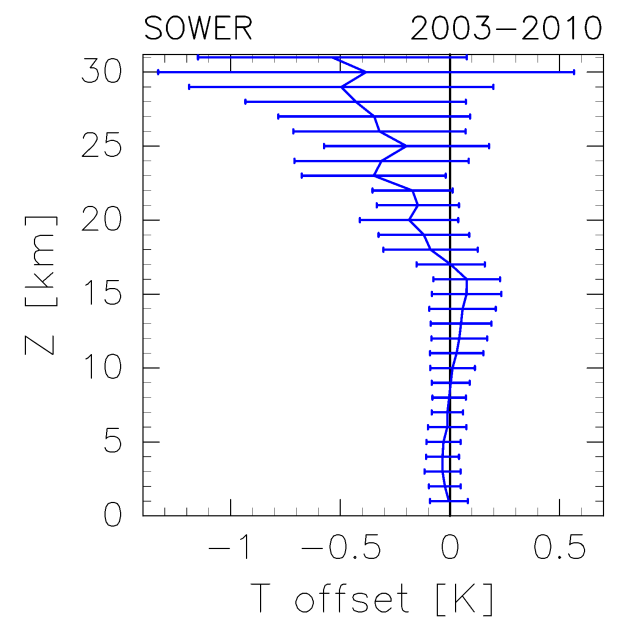

Figure 4. Temperature bias caused by the RS80 pressure bias via the altitude error estimated for all soundings listed in Table 1. Horizontal bars indicate one standard deviation.

nal profile using $Z_{\mathrm{PTU}}$ lies on the upper side of the corrected profile based on $Z$, because there is a positive offset as seen in Fig. 1. To calculate differences between $T\left(Z_{\mathrm{PTU}}\right)$ and $T$ $(Z)$ on the geopotential height $(Z)$ as the "comparison on geopotential height levels" not the"simultaneous sensor comparison", we need data points for $T(Z)$ and $T$ ( $\left.Z_{\text {PTU }}\right)$ at the same geopotential height, because the observation time at the same $Z$ and $Z_{\text {PTU }}$ is different. Thus, we map $T$ ( $Z_{\text {PTU }}$ ) on the $Z$ coordinate so as to define $T_{\mathrm{PTU}}(Z)$ by using $Z$ in place of $Z_{\text {PTU }}\left(T_{\text {PTU }}(Z) \equiv T\left(Z_{\text {PTU }}\right)\right)$.

The difference $\delta T(Z)\left(\equiv T_{\mathrm{PTU}}(Z)-T(Z)\right)$ is shown in the right panel of Fig. 3. Because of the vertical shift, we usually see negative values in the stratosphere where temperature in- 

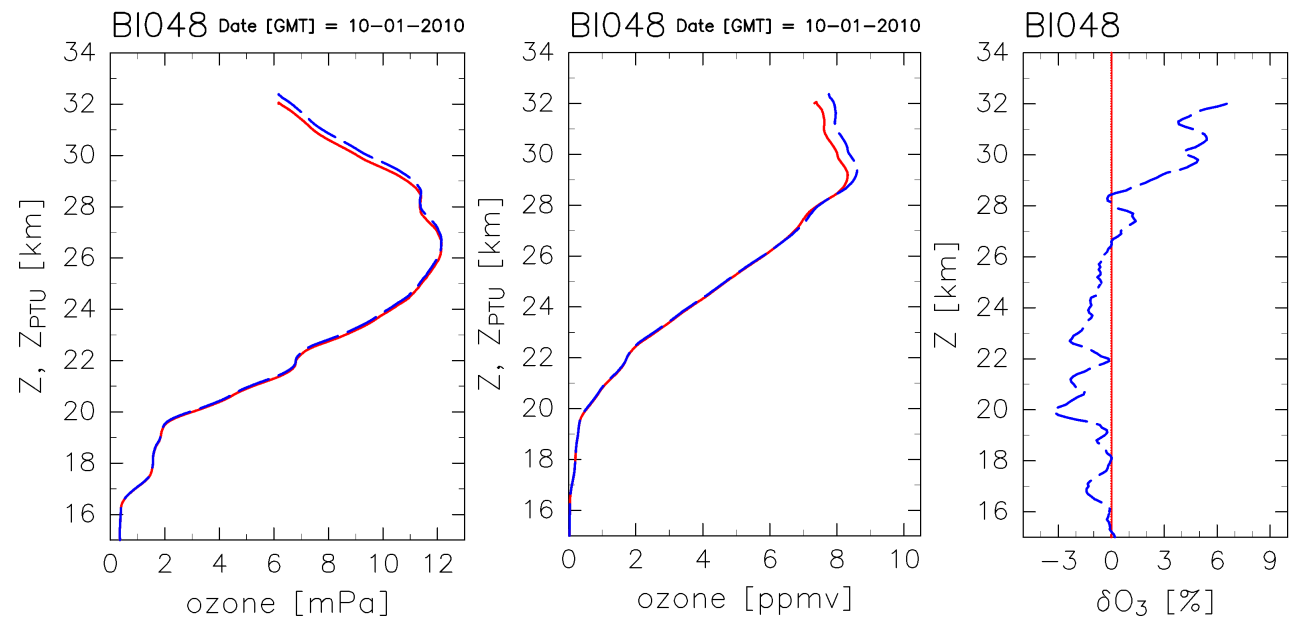

Figure 5. As for Fig. 3 but for (left) ozone partial pressure $\left(p \mathrm{O}_{3}\left(Z_{\mathrm{PTU}}\right) \equiv p \mathrm{O}_{3 \mathrm{PTU}}(Z)\right.$ shown by blue dashed line and $p \mathrm{O}_{3}(Z)$ by the red line) and (center) ozone mixing ratio $\left(\chi \mathrm{O}_{3}\left(Z_{\mathrm{PTU}}\right) \equiv \chi \mathrm{O}_{3 \text { PTU }}(Z)\right.$ shown by the blue dashed line, and $\chi \mathrm{O}_{3}(Z)$ by the red line). (Right) Difference in the ozone profiles for partial pressure and mixing ratio $\left(p \mathrm{O}_{3 \mathrm{PTU}}(Z)\right.$ minus $p \mathrm{O}_{3}(Z)$ or $\chi \mathrm{O}_{3 \mathrm{PTU}}(Z)$ minus $\chi \mathrm{O}_{3}(Z)$; blue dashed line).

creases with increasing height. At around $30 \mathrm{~km}$, an altitude shift of $230 \mathrm{~m}$ can produce a negative temperature offset of about $-1.2 \mathrm{~K}$. This temperature offset is easily confirmed as the vertical gradient of temperature $\left(5.0 \mathrm{~K} \mathrm{~km}^{-1}\right.$ in this case) multiplied by the vertical shift $(0.23 \mathrm{~km}$ in this case). We also see some fluctuations in the temperature differences associated with gravity waves and/or equatorial waves.

Figure 4 shows an average temperature offset; i.e., the average difference of the two temperature profiles, $T_{\text {PTU }}(Z)$ and $T(Z)$ for all available soundings listed in Table 1 . In the stratosphere, the temperature offset tends to increase with increasing altitude, and it is approximately $-0.2 \pm 0.2$, $-0.2 \pm 0.4$, and $-0.4 \pm 0.9 \mathrm{~K}(1 \sigma)$ at 20,25 , and $30 \mathrm{~km}$, respectively. This result is almost consistent with temperature change expected for a pressure sensor changeover from RS80 to RS92 shown in Steinbrecht et al. (2008), but their estimate is somewhat smaller (larger) than our result in the lower (middle) stratosphere. This discrepancy may be caused by a difference of temperature profile between the tropics and mid-latitude.

\subsection{Ozone}

The vertical shift of the height coordinate caused by the RS 80 pressure bias can also affect other observation parameters. Shiotani (2013) argued that what we really need to know as ozonesonde users is the difference between the true profile obtained using a GPS unit and the observed profile obtained using a conventional pressure sensor. However, the result in Stauffer et al. (2014) applies only to those cases where we can use coincident ozone data with pressure information derived from the GPS height to calculate the ozone mixing ratios correctly. The ECC ozonesonde reports ozone partial pressure as its measurement principle (e.g., Johnson et al.,

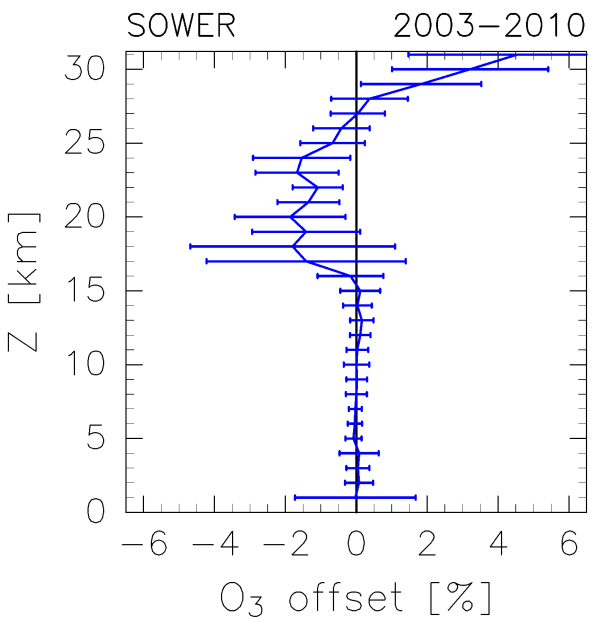

Figure 6. As for Fig. 4 but for ozone partial pressure and mixing ratio.

2002). The left panel of Fig. 5 shows two vertical profiles of ozone partial pressure, one using $Z_{\mathrm{PTU}}\left(p \mathrm{O}_{3}\left(Z_{\mathrm{PTU}}\right) \equiv\right.$ $\left.p \mathrm{O}_{3 \text { PTU }}(Z)\right)$ and the other $Z\left(p \mathrm{O}_{3}(Z)\right)$, as for Fig. 3. The profiles are taken from the same sounding as shown in Fig. 3. In the tropical region, ozone partial pressure has a maximum at approximately $27 \mathrm{~km}$; consequently, the vertical gradient changes from positive to negative at around this level with increasing height.

As the ozone mixing ratio $\left(\chi \mathrm{O}_{3}\right)$ is obtained by dividing ozone partial pressure by atmospheric pressure, the atmospheric pressure bias can lead to an error in the ozone mixing ratio. This effect has already been discussed by Stauffer et al. (2014), based on the following definition of the ozone mixing 

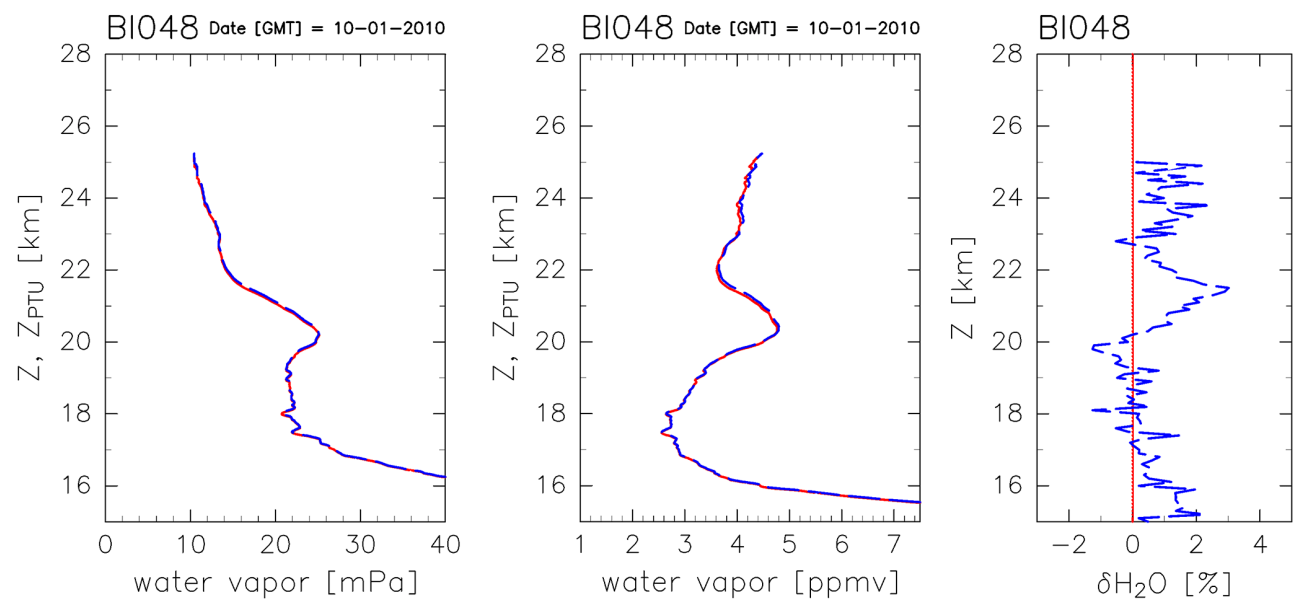

Figure 7. As for Fig. 3 but for (left) water vapor partial pressure $\left(p \mathrm{H}_{2} \mathrm{O}\left(Z_{\mathrm{PTU}}\right) \equiv p \mathrm{H}_{2} \mathrm{O}_{\mathrm{PTU}}(Z)\right.$ shown by the blue dashed line, and $p \mathrm{H}_{2} \mathrm{O}(Z)$ by the red line) and (center) water vapor mixing ratio $\left(\chi \mathrm{H}_{2} \mathrm{O}\left(Z_{\mathrm{PTU}}\right) \equiv \chi \mathrm{H}_{2} \mathrm{O}_{\mathrm{PTU}}(Z)\right.$ shown by the blue dashed line, and $\chi \mathrm{H}_{2} \mathrm{O}(Z)$ by the red line). (Right) Difference in the ozone profiles for partial pressure and mixing ratio $\left(p \mathrm{H}_{2} \mathrm{O}_{\mathrm{PTU}}(Z)\right.$ minus $p \mathrm{H}_{2} \mathrm{O}(Z)$ or $\chi \mathrm{H}_{2} \mathrm{O}_{\mathrm{PTU}}(Z)$ minus $\chi \mathrm{H}_{2} \mathrm{O}(Z)$; blue dashed line).

ratio error $\left(\delta \chi \mathrm{O}_{3}\right)$ :

$\delta \chi \mathrm{O}_{3}(Z)=\frac{\chi \mathrm{O}_{3}\left(Z_{\mathrm{PTU}}\right)-\chi \mathrm{O}_{3}(Z)}{\chi \mathrm{O}_{3}(Z)}$,

where $\chi \mathrm{O}_{3}\left(Z_{\mathrm{PTU}}\right)$ and $\chi \mathrm{O}_{3}(Z)$ are $p \mathrm{O}_{3}\left(Z_{\mathrm{PTU}}\right) / p\left(Z_{\mathrm{PTU}}\right)$ and $p \mathrm{O}_{3}(Z) / p_{\mathrm{GPS}}(Z)$, respectively. Note that Stauffer et al. (2014) used these ozone partial pressures and atmospheric pressures at the same observation time when they evaluated the ozone mixing ratio error (their Fig. 7). However, as we have already explained, there is a difference between $Z_{\text {PTU }}$ and $Z$, and the mixing ratio error $\left(\delta \chi \mathrm{O}_{3}\right)$ should be examined at the same altitude.

The middle panel of Fig. 5 is the same profile as in the left panel, but for the ozone mixing ratio. The mixing ratio error can be estimated as the difference between the original mixing ratio based on $Z_{\text {PTU }}\left(\chi \mathrm{O}_{3}\left(Z_{\text {PTU }}\right) \equiv \chi \mathrm{O}_{3 \text { PTU }}(Z)\right)$; blue dashed line) and the mixing ratio based on $Z\left(\chi \mathrm{O}_{3}(Z)\right.$; red line) at the same geopotential height. As $\chi \mathrm{O}_{3 \text { PTU }}(Z) \equiv$ $p \mathrm{O}_{3 \text { PTU }}(Z) / p(Z)$, Eq. (2) should be replaced by the following equation:

$$
\begin{aligned}
\delta \chi \mathrm{O}_{3}(Z) & =\frac{\chi \mathrm{O}_{3 \mathrm{PTU}}(Z)-\chi \mathrm{O}_{3}(Z)}{\chi \mathrm{O}_{3}(Z)} \\
& =\frac{\frac{p \mathrm{O}_{3 \mathrm{PTU}}(Z)}{p(Z)}-\frac{p \mathrm{O}_{3}(Z)}{p_{\mathrm{GPS}}(Z)}}{\frac{p \mathrm{O}_{3}(Z)}{p_{\mathrm{GPS}}(Z)}} .
\end{aligned}
$$

If temperature and humidity are uniform in vertical, $p_{\mathrm{GPS}}(Z)$ is exactly equal to $p(Z)$. Therefore, the percentage error of mixing ratio exactly corresponds to the percentage error of partial pressure. In reality, however, temperature and humidity are not uniform, so these vertical profile shifts make $p_{\mathrm{GPS}}(Z)$ different from $p(Z)$ at the same geopotential height. Nevertheless, the differences are very small. For example, $0.5 \mathrm{~K}$ of temperature offset in the stratosphere (e.g., $30 \mathrm{~km}$ ) where temperature is $230 \mathrm{~K}$ produces only $0.2 \%$ pressure difference (i.e., $0.5 / 230 \mathrm{~K}$ ). This is much smaller than the ozone partial pressure offsets estimated in this section. Therefore, Eq. (3) is almost the same as the error for ozone partial pressure with an uncertainty of $0.2 \%$. Hence we present only the error for partial pressure representing both errors and simply write the two as $\delta \mathrm{O}_{3}$. The right panel of Fig. 5 shows such a percentage difference for $\delta \mathrm{O}_{3}(Z)$. As expected from the left panel, it changes sign at around $27 \mathrm{~km}$.

Figure 6 shows an average percentage difference calculated from all available soundings. Although the offset is small in the troposphere, it becomes larger in the lower stratosphere with a negative peak at around $20 \mathrm{~km}$. At around $27 \mathrm{~km}$, where there is a maximum of ozone partial pressure, the sign of ozone offset changes. The ozone offset is estimated to be $-1.9 \pm 1.6,-0.7 \pm 0.9$, and $3.2 \% \pm 2.2 \%(1 \sigma)$ at 20,25 , and $30 \mathrm{~km}$, respectively.

Stauffer et al. (2014) found that the pressure bias of the RS80 was $-1 \mathrm{hPa}$, which is somewhat larger than ours, as was their resulting ozone mixing ratio offset, which exponentially increases with increasing altitude. According to Fig. 7 in their paper, the ozone mixing ratio offset was approximately 2,4 , and $10 \%$ at 20,25 , and $30 \mathrm{~km}$, respectively. These estimates are based on $p_{\text {GPS }}$ derived from the coincident GPS altitude. On the other hand, we estimated the RS80 pressure bias in such a case to be $-0.4 \mathrm{hPa}$, and the subsequent ozone offset to be negative $(-1$ to $-2 \%)$ at around $20-25 \mathrm{~km}$, but positive ( $3 \%$ ) at $30 \mathrm{~km}$, which is not an exponential increase with increasing altitude. 


\subsection{Water vapor}

Profiles of water vapor in the stratosphere are observed using a chilled-mirror hygrometer that measures the frostpoint temperature as its measurement principle (e.g., Vömel et al., 2007): such a high-performance hygrometer is necessary for this analysis. A profile of water vapor partial pressure and mixing ratio can be estimated from the frostpoint temperature using the Goff-Gratch equation (Goff and Gratch, 1946; List, 1984). In the SOWER campaign, water vapor profiles for the tropical lower stratosphere, as well as the troposphere, were observed using such chilled-mirror hygrometers.

A vertical profile of water vapor partial pressure based on $Z_{\mathrm{PTU}}\left(p \mathrm{H}_{2} \mathrm{O}\left(Z_{\mathrm{PTU}}\right) \equiv p \mathrm{H}_{2} \mathrm{O}_{\mathrm{PTU}}(Z)\right.$; blue dashed line $)$ and a profile based on $Z\left(p \mathrm{H}_{2} \mathrm{O}(Z)\right.$; red line) are shown in the left panel of Fig. 7. The water vapor mixing ratio is obtained by dividing partial pressure by atmospheric pressure $\left(\chi \mathrm{H}_{2} \mathrm{O} \equiv p \mathrm{H}_{2} \mathrm{O} / p\right)$; two profiles based on $Z_{\mathrm{PTU}}\left(\chi \mathrm{H}_{2} \mathrm{O}\left(Z_{\mathrm{PTU}}\right) \equiv \chi \mathrm{H}_{2} \mathrm{O}_{\mathrm{PTU}}(Z)\right)$ and $Z\left(\chi \mathrm{H}_{2} \mathrm{O}(Z)\right)$ are shown in the middle panel. As for ozone, because the percentage error in partial pressure $\left(\delta p \mathrm{H}_{2} \mathrm{O}\right)$ and that of the mixing ratio $\left(\delta \chi \mathrm{H}_{2} \mathrm{O}\right)$ become almost the same at the same altitude with an uncertainty of $0.2 \%$ (see Eqs. 2-3), we present only the error for partial pressure representing both errors and simply write the two as $\delta \mathrm{H}_{2} \mathrm{O}$, and such a percentage error is shown in the right panel of Fig. 7.

As is well known, the water vapor profile in the tropical lower stratosphere has a "tape recorder" signal (Mote et al., 1996; Fujiwara et al., 2010), and we can see such a signal in the vertical structure of the water vapor mixing ratio profile in Fig. 7, with the minimum at around $18 \mathrm{~km}$, the maximum at around $20.5 \mathrm{~km}$, and a weaker minimum at around $22 \mathrm{~km}$. This vertical structure is similar to those profiles measured at Costa Rica in December-January-February 2008 shown in Fig. 3 of Fujiwara et al. (2010). As their observation period was 2 years earlier than that of the BI048 observations, the two periods should be in a similar phase of the stratospheric quasi-biennial oscillation (QBO). The water vapor partial pressure profile also has a vertical structure corresponding to that of the mixing ratio, and $\delta \mathrm{H}_{2} \mathrm{O}$ changes sign associated with the water vapor maximum at $20.5 \mathrm{~km}$, as shown in the right panel.

An average percentage difference for water vapor calculated from all available soundings is shown in Fig. 8. The average error in the water vapor profiles was estimated to be $-0.9 \% \pm 2.1 \%$ at $18 \mathrm{~km}$ and $1.4 \% \pm 0.9 \%(1 \sigma)$ at $21 \mathrm{~km}$ associated with the tape recorder signal. The altitudes of the cold point tropopause (CPT) and water vapor minima near the CPT vary seasonally and interannually. To focus on offsets near the CPT, where the water vapor profiles have a steep gradient and minimum, we aligned the water vapor profiles according to the water vapor minimum. Figure 9 shows the average error based on relative altitude with reference to that of the water vapor minimum around the CPT. We can see that the offset is clearer than that in Fig. 8, and is estimated to be

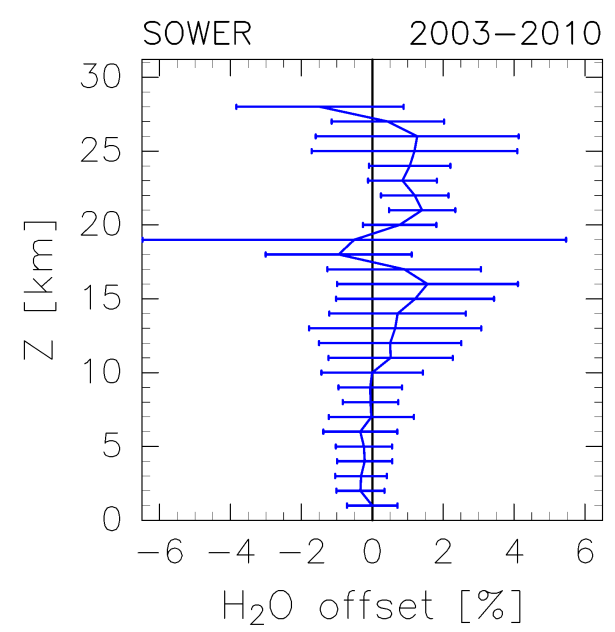

Figure 8. As for Fig. 4 but for water vapor partial pressure and mixing ratio.

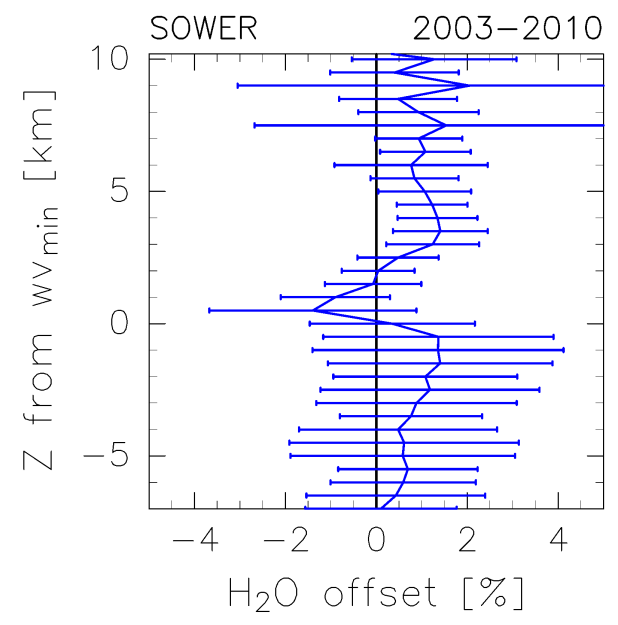

Figure 9. As for Fig. 8 but for the biases based on relative altitude with reference to that of the water vapor minimum near the CPT.

$-1.4 \% \pm 2.3 \%$ at $0.5 \mathrm{~km}$ and $1.4 \% \pm 1.0 \%(1 \sigma)$ at $3.5 \mathrm{~km}$ above the water vapor minimum. As there is a negative and steep gradient of water vapor abundance in the upper troposphere, a small positive error of $z$ PTU produces a positive water vapor error at around $16 \mathrm{~km}$ in Fig. 8, and also below the water vapor minimum in Fig. 9. We note here that this result is based on limited soundings obtained during the boreal winter and that the vertical distribution of water vapor error in the stratosphere may differ somewhat from this result depending on the phase of the tape recorder signal. It should be noted that the results are based on approximately $20 \mathrm{~m}$ of the altitude offset near the cold-point tropopause. This value is comparable to the uncertainty of the geopotential height and also to the uncertainty of the GPS unit. Also, the uncertainty of CFH measurements is estimated to be $9 \%$ or smaller in the upper troposphere and lower stratosphere (Vömel et al., 
2007). This value is larger than water vapor offset due to the pressure biases of RS80.

\section{Discussion}

As described above, the RS80 pressure bias leads to temperature, ozone, and water vapor offsets. If we assume that RS80 radiosondes without a GPS unit were switched to new radiosondes with a GPS unit during the period 2000-2010, we would expect to see such offsets in the meteorological parameters that may affect any trend analysis that covers this period. In this section, we discuss issues related to long-term trends in temperature, ozone, and water vapor, together with the possible impacts on these trends of offsets associated with altitude misestimation.

Ladstädter et al. (2011) estimated temperature trends from satellite, sonde, and GPS radio occultation (RO) data between 2001 and 2010. This includes the period when the RS80 was progressively replaced by the new radiosonde system. They reported warming trends from 13 to $25 \mathrm{~km}$ over the tropics, as well as whole latitude region, and that the trend obtained from sonde measurements was $0.2 \mathrm{~K} \mathrm{dec}^{-1}$ higher than that obtained from satellite observations. The altitude range for their trend analysis included both the troposphere and the stratosphere, as they focused on a comparison with satellite data having a coarse vertical resolution. The discrepancy between the trends based on the sonde and satellite measurements can be interpreted to be caused by the RS80 temperature offset estimated in this study, as it is consistent with the value $(+0.2 \mathrm{~K})$ averaged over $13-25 \mathrm{~km}$ from Fig. 3. At the same time, however, Ladstädter et al. (2011) reported a comparable trend from GPS RO measurements to that from sonde measurements. These temperature trends should be estimated as a function of altitude and be compared in the troposphere and the stratosphere separately.

Randel and Thompson (2011) reported that the ozone mixing ratio follows a negative trend of -4 and $-0.5 \% \mathrm{dec}^{-1}$ in the stratosphere from 17 to $23 \mathrm{~km}$ and from 23 to $30 \mathrm{~km}$, respectively, based on measurements from the Stratospheric Aerosol and Gas Experiment II (SAGE II) satellite (19842005) and the Southern Hemisphere Additional Ozonesondes (SHADOZ) network (1998-2009). They pointed out that the negative trends in the lower stratosphere are a dynamical response to enhanced tropical upwelling. On the other hand, Gabhardt et al. (2014) reported positive trends in the same altitude region based on SCanning Imaging Absorption spectroMeter for Atmospheric CHartographY (SCIAMACHY) satellite measurements (2002-2012). In particular, they argued that the positive trend between 25 and $30 \mathrm{~km}$ cannot be explained in terms of enhanced tropical upwelling.

As discussed above, a switch from the RS80 to the new GPS radiosondes may create an artificial ozone trend; i.e., a positive trend of $1-2 \% \mathrm{dec}^{-1}$ at around $20 \mathrm{~km}$, and a negative trend of $-3 \% \mathrm{dec}^{-1}$ at $30 \mathrm{~km}$. It is possible that the negative trend is larger than that estimated by Randel and Thompson (2011) in view of the present results.

In addition to the annual variations reflected in the tape recorder signal, water vapor abundance in the upper troposphere and lower stratosphere shows interannual variations depending on the El Ninõ-Southern Oscillation (ENSO) and the QBO (e.g., Randel et al., 2004). For longer-term variations, Hurst et al. (2011) reported that water vapor in the mid-latitude lower stratosphere from 16 to $26 \mathrm{~km}$ decreased during the period 2001-2005 by an average of $0.4 \mathrm{ppmv}$, then increased again during the period 2006-2010 by an average of $0.5 \mathrm{ppmv}$. As for temperature and ozone, the water vapor offset caused by the altitude misestimation affects these water vapor observation records, and the offsets are estimated to be approximately $-1.5-1.5 \%$, depending on altitude, in the lower stratosphere.

Whereas the water vapor offset is smaller than its stratospheric trend, those for temperature and ozone are comparable in magnitude to their decadal trends in the lower stratosphere. Therefore, these long-term variations should be discussed after examining and correcting these radiosonde errors.

In this study, we proposed an appropriate approach how to deal with historical data sets affected by the pressure sensor biases. We recommend for the radiosonde/ozonesonde/water vapor sonde communities to apply this method to historical data sets (one example of correction for sounding data without a GPS unit shown in Appendix B) to improve our understanding of the stratospheric temperature, ozone, and water vapor trends.

\section{Summary}

At present, GPS technology is used to measure altitude, and pressure is inversely derived from the GPS height data. Although the Vaisala RS80 radiosonde was used worldwide from 1981, such old-type radiosondes without a GPS receiver have been replaced by new-type radiosondes with a GPS receiver over the past decade. Recently, it has been reported that the RS80 radiosonde shows a negative pressure bias in the stratosphere (e.g., Steinbrecht et al., 2008; Inai et al., 2009).

There are two methods for comparison of two simultaneous radiosonde sounding data, i.e., the "simultaneous sensor comparison" and the "comparison on pressure (or altitude or geopotential height) levels". Stauffer et al. (2014) evaluated ozone mixing ratio errors caused by pressure biases from various types of conventional radiosondes, but they used the former method for the evaluation. The latter method, however, is useful for the researchers who are considering to make corrections and data homogenization of conventional sounding data without GPS units.

In this study, we evaluate sounding errors associated with the RS80 pressure biases in conventional sounding data using 
an approach of the "comparison on geopotential height levels. We estimated that the pressure bias in the tropical stratosphere, as assessed using the SOWER data set for the period from December 2003 to January 2010, is $-0.4 \pm 0.2 \mathrm{hPa}(1 \sigma)$ from 20 to $30 \mathrm{~km}$. We also estimated that this pressure bias could lead to an altitude misestimation of $43 \pm 23,110 \pm 40$, and $240 \pm 92 \mathrm{~m}(1 \sigma)$ at 20,25 , and $30 \mathrm{~km}$, respectively.

This altitude misestimation can lead to offsets in other meteorological profiles, such as temperature, ozone, and water vapor. We found that in the stratosphere the temperature offset caused by such altitude misestimation tends to increase with increasing altitude, and it is approximately $-0.2 \pm 0.2$, $-0.2 \pm 0.4$, and $-0.4 \pm 0.9 \mathrm{~K}(1 \sigma)$ at 20,25 , and $30 \mathrm{~km}$, respectively. On the other hand, for the ozone offset its sign changes at $27 \mathrm{~km}$ where there is a maximum of ozone partial pressure, and it is estimated to be $-1.9 \pm 1.6,-0.7 \pm 0.9$, and $3.2 \% \pm 2.2 \%(1 \sigma)$ at 20,25 , and $30 \mathrm{~km}$, respectively. For water vapor, there is a minimum and maximum in the tropical lower stratosphere associated with the tape recorder signal. Thus, the water vapor offset is affected by the phase of the tape recorder and is estimated to be $-1.4 \pm 2.3 \%$ at $0.5 \mathrm{~km}$ and $1.4 \% \pm 1.0 \%(1 \sigma)$ at $3.5 \mathrm{~km}$ above the water vapor minimum around the cold point tropopause.

These temperature, ozone, and water vapor offsets may produce an artificial change in long-term meteorological records at the time when the radiosonde system changed from the RS80 to the new model. Therefore, we must take these issues into account if we are to compile accurate meteorological data sets and improve our understanding of climate change. 


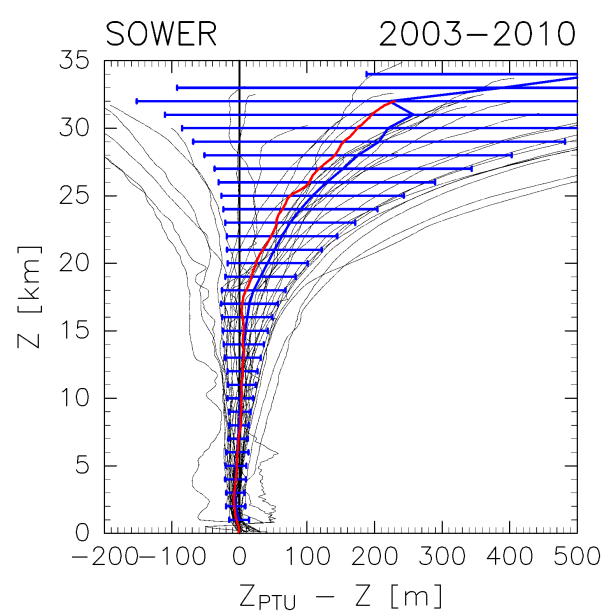

Figure A1. As for Fig. 1 but for profiles using non-QC data.

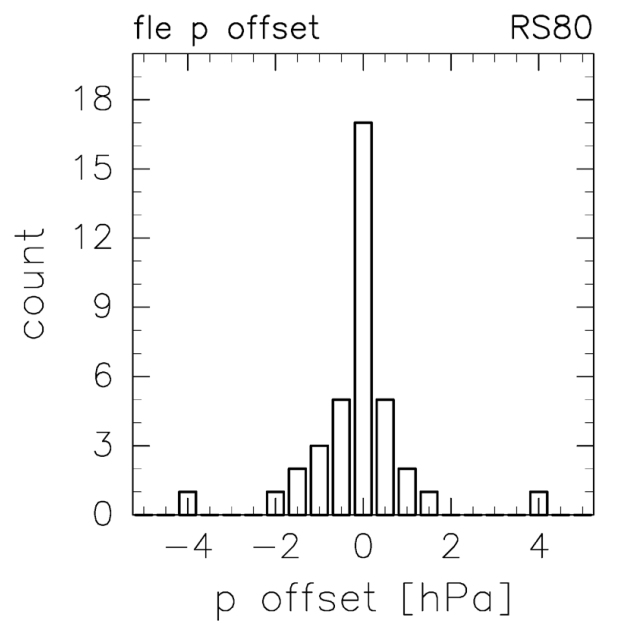

Figure A2. Frequency distribution of pressure offset, which was empirically determined using our QC procedure. The data are split into $\pm 0.25 \mathrm{hPa}$ bins with an increment of $0.5 \mathrm{hPa}$ and a total of 38 soundings.

\section{Appendix A}

Here, we describe how we processed the original pressure profiles prior to analysis. Each pressure sensor in the RS80 radiosondes has its own uncertainty, in addition to the pressure bias described in this paper. If we plot the differences between $z_{\mathrm{PTU}}$ and $z$, similar to Fig. 1 but using uncorrected (original) profiles, the result is as in Fig. A1. We see larger variability of profiles in this figure than in Fig. 1, because original pressure information sometimes includes a large error. To reduce this variation, we made a correction by using a constant offset value for the entire height range. The correction value was subjectively determined to fit a profile to the average. A frequency distribution of the correction values for pressure offset is shown in Fig. A2. On the basis of these statistics, we excluded five profiles using the criterion
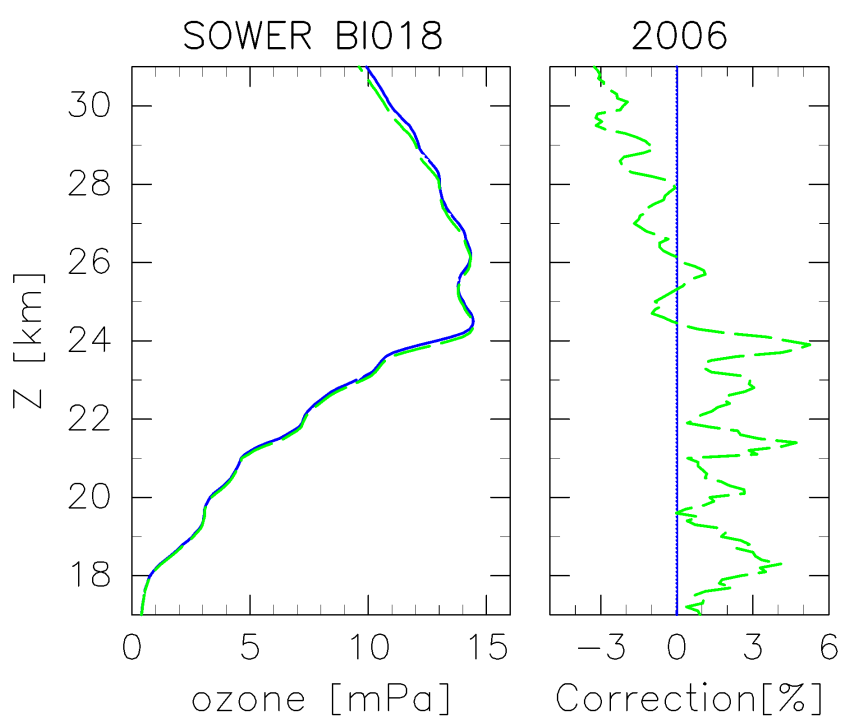

Figure B1. (Left) Profile of ozone partial pressure measured without a GPS unit at 22:18 on 13 January 2006 (UT) (blue line) and that recalculated with corrected pressure by subtracting the pressure bias shown in Fig. 2 from the original value (green dashed line). (Right) Percentage of correction amount due to the pressure correction (green dashed line).

that the absolute value of the pressure offset should not be larger than $1.5 \mathrm{hPa}$, and so used 33 soundings (out of a total of 38) in this study.

\section{Appendix B}

We show an attempt to correct sounding errors without GPS information using a sounding example of the SOWER data measured without a GPS unit. Figure B1 shows an original and a corrected profiles of ozone partial pressure measured without a GPS unit and the difference between the two. Even if we can not perfectly evaluate sounding errors and correct them when an ozonesonde (or a water vapor sonde) is launched without GPS units, we can correct them if we assume that a statistical characteristic of radiosonde pressure bias in data set measured without GPS units would not differ from that in this study, which is shown in Fig. 2. On the basis of this assumption, the profile in green was recalculated with corrected pressure by subtracting the bias from its original pressure value. 
Acknowledgements. The authors are grateful to SOWER colleagues, K. Shimizu, S.-Y. Ogino, S. Iwasaki, N. Nishi, and T. Shibata for their assistance. We also thank the members of Lembaga Penerbangan dan Antariksa Nasional (LAPAN) of Indonesia, and the Meteorological Office of Tarawa, Kiribati. This work was supported by KAKENHI, Japan Society for the Promotion of Science, Japan (15204043, 16740264, 18204041, and 21244072), and the Global Environment Research Fund of the Ministry of the Environment (A-1 and A-071). The figures were produced by the GFD-DENNOU Library. We also thank three anonymous reviewers and Ryan Stauffer for valuable comments.

Edited by: A. Stoffelen

\section{References}

da Silveira, R., Fisch, G., Machado, L., Dall'Antonia, A., Sapucci, L., Fernandes, D., and Marques, R.: WMO intercomparison of GPS radiosondes, Alcantara, Brazil, 2001, WMO/TD No. 1314, Instruments and Observing Methods Report No. 90, World Meteorological Organization, Geneva, 65 pp., 2006.

Elms, J.: WMO catalogue of radiosondes and upper-air wind systems in use by members in 2002 and compatibility of radiosonde geopotential measurements for period from 1998 to 2001, Report No. 80, WMO/TD No. 1197, World Meteorological Organization, Geneva, 2003.

Fujiwara, M., Vömel, H., Hasebe, F., Shiotani, M., Ogino, S.Y., Iwasaki, S., Nishi, N., Shibata, T., Shimizu, K., Nishimoto, E., Canossa, J. M. V., Selkirk, H. B., and Oltmans, S. J.: Seasonal to decadal variations of water vapor in the tropical lower stratosphere observed with balloon-borne cryogenic frost point hygrometers, J. Geophys. Res., 115, D18304, doi:10.1029/2010JD014179, 2010.

Gebhardt, C., Rozanov, A., Hommel, R., Weber, M., Bovensmann, H., Burrows, J. P., Degenstein, D., Froidevaux, L., and Thompson, A. M.: Stratospheric ozone trends and variability as seen by SCIAMACHY from 2002 to 2012, Atmos. Chem. Phys., 14, 831-846, doi:10.5194/acp-14-831-2014, 2014.

Goff, A. J. and Gratch, S.: Low-pressure properties of water from -160 to $212^{\circ}$ F, Trans. Amer. Soc. Heat. Vent. Eng., 52, 95-122, 1946.

Hasebe, F., Inai, Y., Shiotani, M., Fujiwara, M., Vömel, H., Nishi, N., Ogino, S.-Y., Shibata, T., Iwasaki, S., Komala, N., Peter, T., and Oltmans, S. J.: Cold trap dehydration in the Tropical Tropopause Layer characterised by SOWER chilled-mirror hygrometer network data in the Tropical Pacific, Atmos. Chem. Phys., 13, 4393-4411, doi:10.5194/acp-13-4393-2013, 2013.

Holton, J. R.: An Introduction to Dynamic Meteorology, 4th Edn., Elsevier Academic Press, New York, 535 pp., 2004.

Hurst, D. F., Oltmans, S. J., Vömel, H., Rosenlof, K. H., Sean, M. Davis, S. M., Ray, E. A., Hall, E. G., and Jordan, A. F.: Stratospheric water vapor trends over Boulder, Colorado: analysis of the 30 year Boulder record, J. Geophys. Res., 116, D02306, doi:10.1029/2010JD015065, 2011.

Imai, K., Fujiwara, M., Inai, Y., Manago, N., Suzuki, M., Sano, T., Mitsuda, C., Naito, Y., Hasebe, F., Koide, T., and Shiotani, M.: Comparison of ozone profiles between Superconducting Submillimeter-Wave Limb-Emission Sounder (SMILES) and worldwide ozonesonde measurements, J. Geophys. Res.-Atmos., 118, 12755-12765, doi:10.1002/2013JD021094, 2013.

Inai, Y., Hasebe, F., Shimizu, K., and Fujiwara, M.: Correction of radiosonde pressure and temperature measurements using simultaneous GPS height data, SOLA, 5, 109-112, doi:10.2151/sola.2009-028, 2009.

Inai, Y., Shibata, T., Fujiwara, M., Hasebe, F., and Vömel, H.: High supersaturation inside cirrus in well-developed tropical tropopause layer over Indonesia, Geophys. Res. Lett., 39, L20811, doi:10.1029/2012GL053638, 2012.

Inai, Y., Hasebe, F., Fujiwara, M., Shiotani, M., Nishi, N., Ogino, S.Y., Vömel, H., Iwasaki, S., and Shibata, T.: Dehydration in the tropical tropopause layer estimated from the water vapor match, Atmos. Chem. Phys., 13, 8623-8642, doi:10.5194/acp-13-86232013, 2013.

Ivanov, A., Kats, A., Kurnosenko, S., Nash, J., and Zaitseva, N.: WMO international radiosonde intercomparison phase III (Dzhambul, USSR, 1989) final report (WMO/TD-451), Instrum., and Observ. Methods Rep. 40, World Meteorological Organization, Geneva, 135 pp., 1991.

Jeannet, P., Bower, C., and Calpini, B.: Global Criteria for Tracing the Improvements of Radiosondes over the Last Decades Instruments and Observing Methods, Report No. 95, WMO/TD No. 1433, World Meteorological Organization, Geneva, 2008.

Johnson, B. J., Oltmans, S. J., Vömel, H., Smit, H. G. J., Deshler, T., and Kroger, C.: Electrochemical concentration cell (ECC) ozonesonde pump efficiency measurements and tests on the sensitivity to ozone of buffered and unbuffered ECC sensor cathode solutions, J. Geophys. Res., 107, 4393, doi:10.1029/2001JD000557, 2002.

Kobayashi, E., Noto, Y., Wakino, S., Yoshii, H., Ohyoshi, T., Saito, S., and Baba, Y.: Comparison of Meisei RS2-91 rawinsondes and Vaisala RS92-SGP radiosondes at Tateno for the data continuity for climatic data analysis, J. Meteor. Soc. Japan, 90, 923-945, doi:10.2151/jmsj.2012-605, 2012.

Ladstädter, F., Steiner, A. K., Foelsche, U., Haimberger, L., Tavolato, C., and Kirchengast, G.: An assessment of differences in lower stratospheric temperature records from (A)MSU, radiosondes, and GPS radio occultation, Atmos. Meas. Tech., 4, 1965-1977, doi:10.5194/amt-4-1965-2011, 2011.

List, R. J.: Smithsonian Meteorological Tables, 5th Edn., Smithsonian Institution, Washington, DC, USA, 1984.

Mahoney, M.: A Discussion of Various Measures of Altitude, Tech. rep., NASA Jet Propulsion Laboratory, 2005.

Mote, P. W., Rosenlof, K. H., McIntyre, M. E., Carr, E. S., Gille, J. C., Holton, J. R., Kinnersley, J. S., Pumphrey, H. C., Russell III, J. M., and Waters, J. W.: An atmospheric tape recorder: the imprint of tropical tropopause temperatures on stratosphericwater vapor, J. Geophys. Res., 101, 3989-4006, 1996.

NIMA (National Imagery and Mapping Agency): Department of Defence World Geodetic System 1984 - Its Definition and Relationships with Local Geodetic Systems, NIMA Technical Report, NIMA TR8350.2, 3rd Edn., Amendment 1, 3 January, 2000.

Nash, J. and Schmidlin, F. J.: WMO international radiosonde comparison (UK 1984, USA 1985), Final Report, WMO Instruments and Observing Methods, Report No. 30, WMO/TD-No. 195, Word Meteorol. Org., Geneva, viii +103 pp., 1987. 
Nash, J., Smout, R., Oakley, T., Pathack, B., and Kurnosenko, S.: WMO intercomparison of radiosonde systems, Vacoas, Mauritius, 2-25 February 2005, WMO/TD-No. 1303, 115 pp., 2006.

Nash, J., Oakley, T., Vömel, H., and Wei, L.: WMO intercomparison of high quality radiosonde systems, Yangjiang, China, 12 July-3 August 2010, WMO/TD-No. 1580, 248 pp., available at: http://www.wmo.int/pages/prog/www/IMOP/ publications-IOM-series.html, 2011.

Randel, W. J. and Thompson, A. M.: Interannual variability and trends in tropical ozone derived from SAGE II satellite data and SHADOZ ozonesondes, J. Geophys. Res., 116, D07303, doi:10.1029/2010JD015195, 2011.

Randel, W. J., Wu, F., Oltmans, S. J., Rosenlof, K., and Nedoluha, G. E.: Interannual changes of stratospheric water vapor and correlations with tropical tropopause temperatures, J. Atmos. Sci., 61, 2133-2148, 2004.

Shibata, T., Shibata, T., Hayashi, M., Naganuma, A., Hara, N., Hara, K., Hasebe, F., Shimizu, K., Komala, N., Inai, Y., Vömel, H., Hamdi, S., Iwasaki, S., Fujiwara, M., Shiotani, M., Ogino, S.-Y., and Nishi, N.: Cirrus cloud appearance in a volcanic aerosol layer around the tropical cold point tropopause over Biak, Indonesia, in January 2011, J. Geophys. Res., 117, D11209, doi:10.1029/2011JD017029, 2012.
Shiotani, M.: Shiotani, M.: Interactive Comment on: "Propagation of radiosonde pressure sensor errors to ozonesonde measurements" by R. M. Stauffer et al., Atmos. Meas. Tech. Discuss., 6, C2996-C3000, 2013.

Steinbrecht, W., Claude, H., Schönenborn, F., Leiterer, U., Dier, H., and Lanzinger, E.: Pressure and temperature differences between Vaisala RS80 and RS92 radiosonde systems, J. Atmos. Ocean. Tech., 25, 909-927, 2008.

Stauffer, R. M., Morris, G. A., Thompson, A. M., Joseph, E., Coetzee, G. J. R., and Nalli, N. R.: Propagation of radiosonde pressure sensor errors to ozonesonde measurements, Atmos. Meas. Tech., 7, 65-79, doi:10.5194/amt-7-65-2014, 2014.

Vömel, H., David, D., and Smith, K.: Accuracy of tropospheric and stratospheric water vapor measurements by the cryogenic frost point hygrometer: instrumental details and observations, J. Geophys. Res., 112, D08305, doi:10.1029/2006JD007224, 2007.

Yagi, S., Mita, A., and Inoue, N.: WMO international radiosonde intercomparison phase IV (Tsukuba, Japan, 1993) final report, WMO/TD No. 742, Instruments and Observing Methods Report No. 59, World Meteorological Organization, Geneva, 130 pp., 1996. 